\title{
A New Design of Variable-Geometry TBCC Inlet Based on an Internal Waverider Concept
}

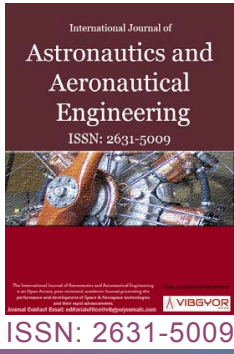

\section{Chen Xia ${ }^{1^{*}}$, Guoping Huang ${ }^{2}$, Ting Yue ${ }^{3}$, Huihui Huang ${ }^{3}$ and Ruilin Wang ${ }^{3}$}

${ }^{1}$ Lecturer, College of Energy and Power Engineering, Nanjing University of Aeronautics \& Astronautics (NUAA), China

${ }^{2}$ Professor, College of Energy and Power Engineering, China

${ }^{3}$ Master Student, College of Energy and Power Engineering, China

\begin{abstract}
The turbine based combined cycle propulsion system, a hopeful air-breathing propulsion system for high speed aircrafts, needs to work in a wide Mach number range. To meet the requirement, the variable-geometry internal waverider inlet based on improved Internal Conical of Flowfield $\mathrm{C}+$ is proposed in this paper. Firstly, the axisymmetric basic flowfield is improved to an Internal Conical of Flowfield $\mathrm{C}+$ with a higher external compression ratio, which befit to relieving the mass flow choke under low Mach number conditions. Secondly, a variable-geometry design method is proposed for the internal waverider and turbine based combined cycle inlet. In order to ensure sealing of variable geometry inlet, a new arrangement of the inlet osculating planes is proposed. And when the inlet geometry varies to expand the throat, the shape of cross-sections always keeps smooth. Such design contributes to a waverider shock structure without corner flows and high efficiency in wide speed range. Finally, CFD results indicate that the internal waverider and turbine based combined cycle inlet exhibits excellent aerodynamic performance characteristics, with high mass flow coefficient and low total pressure loss, thus enabling a great improvement for the turbine based combined cycle system.
\end{abstract}

\section{Keywords}

Internal waverider inlet, Turbine based combined cycle, Variable-geometry, Flow characteristics, Numerical simulation

\section{Nomenclature}

TBCC: Turbine-Based Combined Cycle; RBCC: Rocket-Based Combined Cycle; IWRI: Internal WaveRider Inlet; ICFC+: Internal Conical Flow of C+; FaCET: Falcon combined cycle engine technology; CR: Contraction Ratio; M: Mach number; $\phi$ : mass flow coefficient; $\sigma$ : total pressure recovery; $\pi$ : pres- sure ratio; $\eta_{\mathrm{ke}}$ : kinetic energy efficiency; $\theta$ : rotation angle of the movable surface;

\section{Introduction}

In recent decades, the demand of military competition and weapons equipment in the aerospace field is growing. And the research on high-speed

*Corresponding author: Chen Xia, Lecturer, College of Energy and Power Engineering, Nanjing University of Aeronautics \& Astronautics (NUAA), 29 Yudao St, Nanjing 210016, China

Accepted: May 23, 2020; Published: May 25, 2020

Copyright: (C) 2020 Xia C, et al. This is an open-access article distributed under the terms of the Creative Commons Attribution License, which permits unrestricted use, distribution, and reproduction in any medium, provided the original author and source are credited.

Xia et al. Int J Astronaut Aeronautical Eng 2020, 5:037

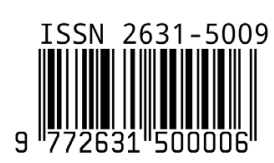


aircraft has been motivated, such as missiles that can execute remote rapid strikes or penetration, supersonic/hypersonic integrated intelligence fighters, surveillance, reconnaissance, reusable launch vehicles and so on. A propulsion system is crucial for high-speed aircraft to achieve a wide range of flight speeds [1-3]. However, there is currently no single type of power propulsion that can cover a wide range of flight Mach numbers. Therefore, the use of a combination of different kinds of propulsion systems is an effective solution, exploiting the advantages of each system in their own optimum speed range. Typical combined propulsion systems include TBCC and RBCC. The TBCC is with large specific impulse, favourable economic performance, repeatable utilization and the capability of taking off/landing horizontally, thus leading to great potential applications in aerospace vehicles. For example, the 558 power propulsion unit [2], which supplies the thrust for the famous "Black Bird" supersonic reconnaissance aircraft, is one kind of air-breathing combined propulsion system.

As a key component for the TBCC system, the inlet should provide an appropriate compressed air flow for the ramjet combustor or turbojet. Thus, high-quality outflows of the inlet are important for improving the overall performance of the TBCC. Typical inlets applied in the TBCC have simple aerodynamic shapes and easily adjustable geometric configurations. For example, the axisymmetric inlet installed in the J58 $[4,5]$ and the two-dimensional inlet installed in X-43B $[6,7]$. However, the aerodynamic performances of these inlets are still not so excellent to satisfy the requirements of high-speed aircrafts. While the recently proposed inward turning inlet has significant advantages over axisymmetric/planar inlets; for instance, the strong ability to capture the air flow, high compression efficiency and low total pressure loss $[8,9]$. If this inlet was applied to the TBCC, the aircraft would benefit from the outstanding performance of the inward turning inlet.

Furthermore, some advanced TBCC programs have adopted inward turning inlets, and in order to enable the inlet to start and operate in low Mach number conditions, a variable-geometry design for the inlet is needed. As shown in Figure 1 and Figure $2[10,11]$, the FaCET engine uses a variable inward turning inlet. The inlet equips a movable diverter flap to distribute the mass flow into the turbojet and ramjet/scramjet. While the internal contraction of the inward turning inlet is beyond the Kantrowitz starting limits, the inlet incorporates a rotating cowl to associate in starting, but the inlet performance in wide working range cannot be compromised. The "Trijet" TBCC scheme (Figure 3) proposed by the Aerojet Corporation also utilizes a streamline-tracing inward turning inlet [12-14], with part of the air flow guided into the turbojet or ejector ramjet passages by the actuation of forward doors and aft doors in the variable-geometry mechanism. But in this case, the shock structure is complex due to the presence of several sharp corners in the flow passages showed in Figure 4, which has great impact on the inlet performance.

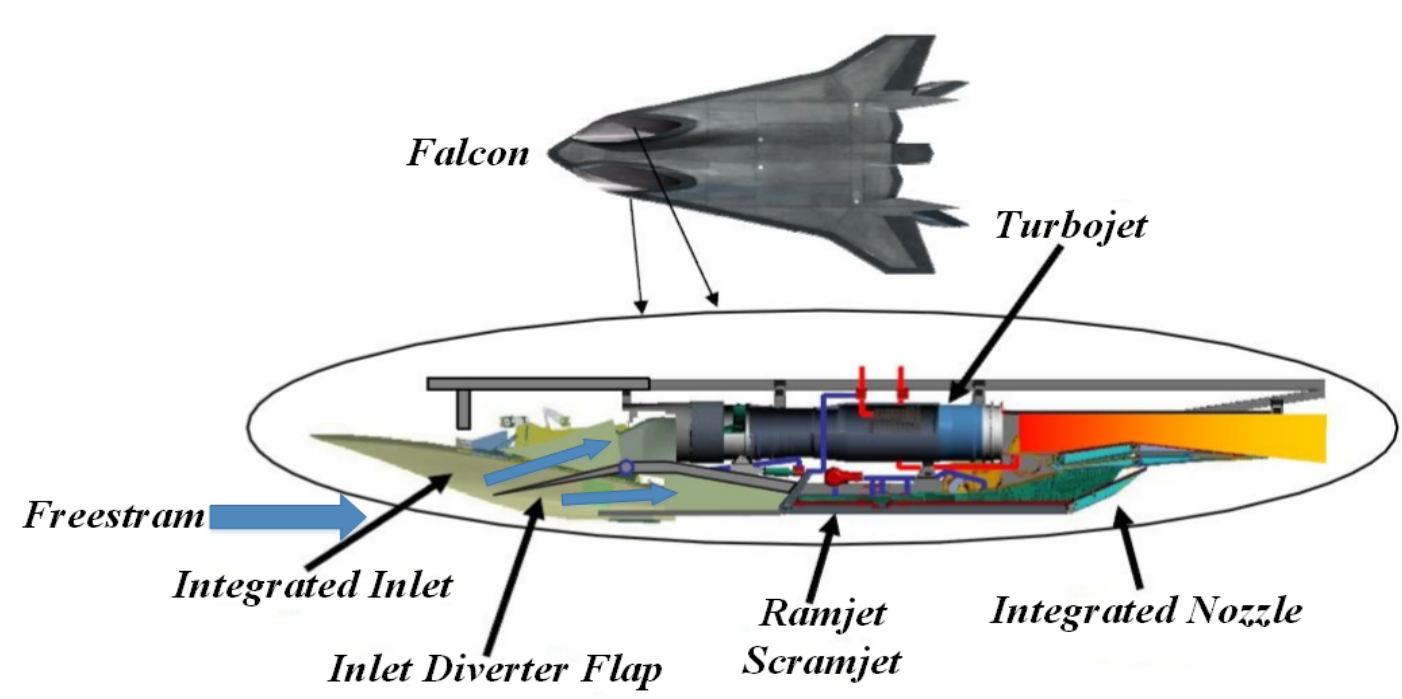

Figure 1: Falcon combined cycle engine technology combined engine. 


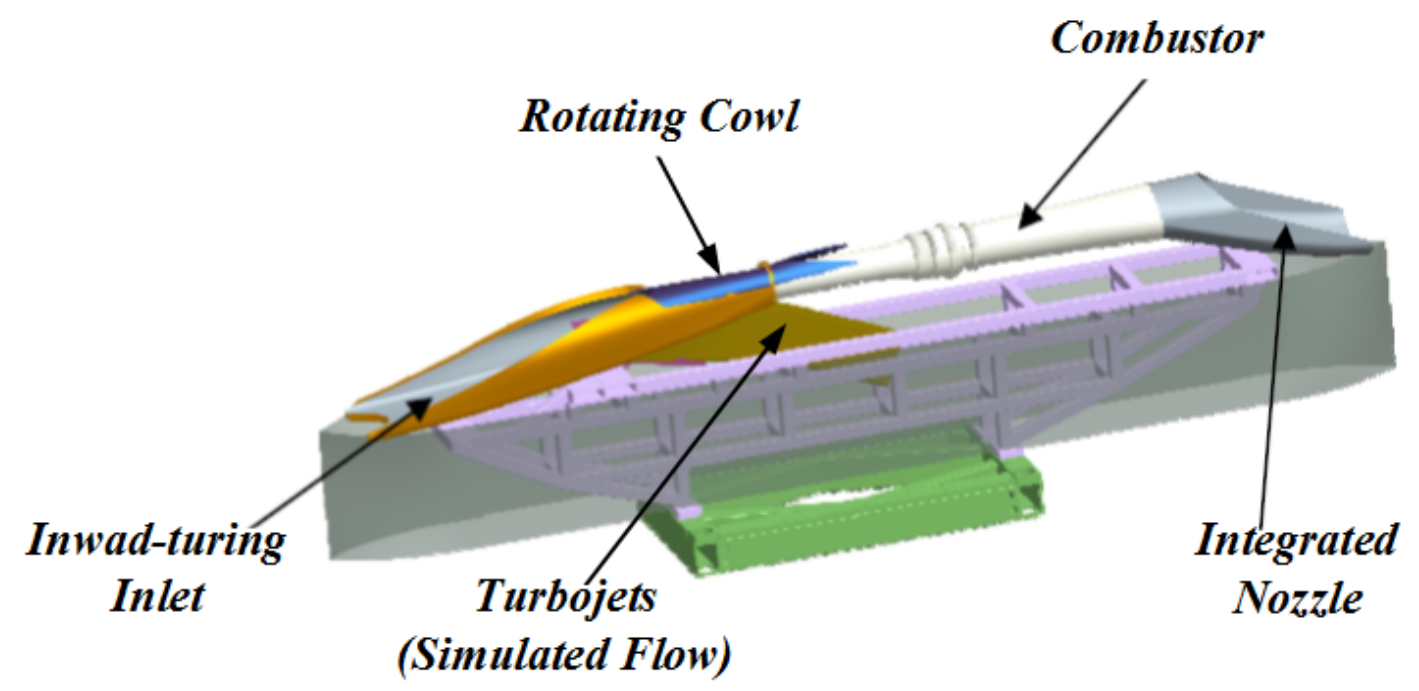

Figure 2: Falcon combined cycle engine technology engine turbine-based combined cycle flow path.

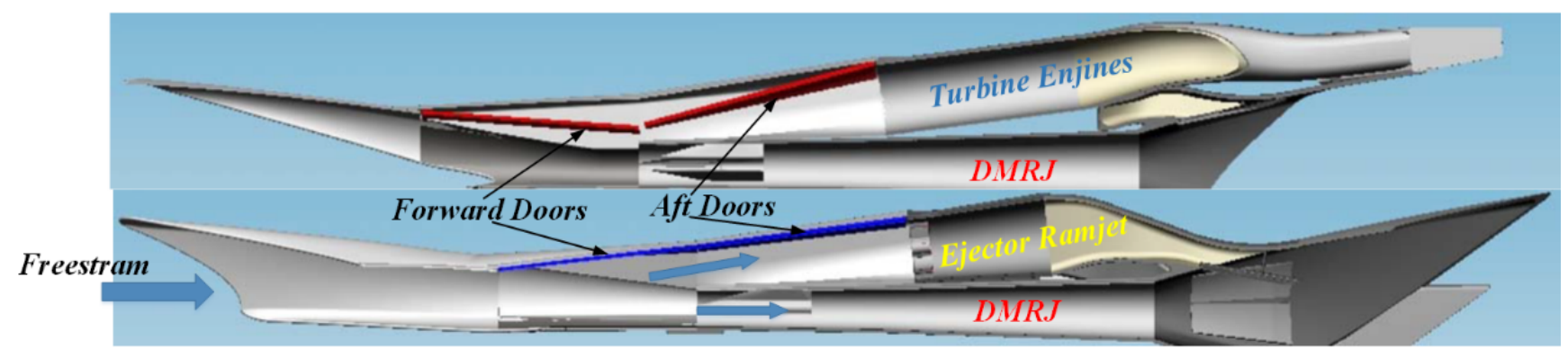

Figure 3: Trijet combined cycle.
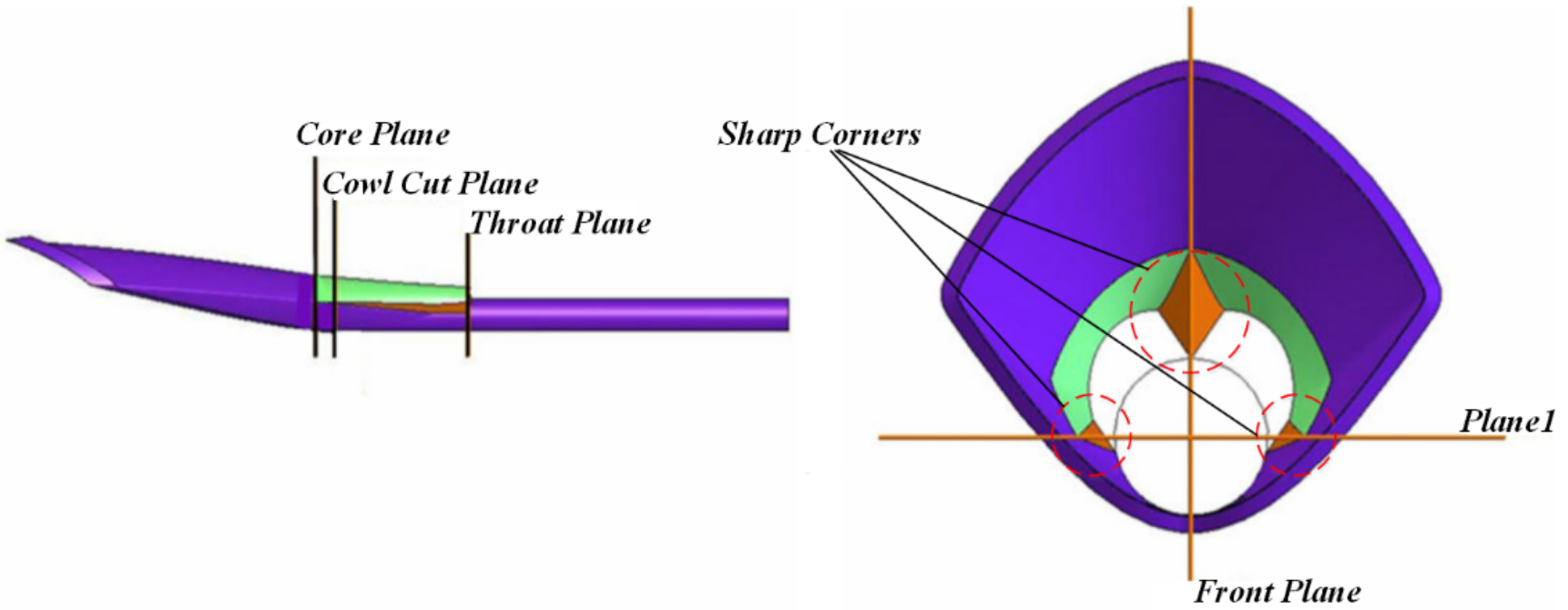

Figure 4: Variable-geometry inward turning inlet of the trijet.

As mentioned above, to enable practical use of the inward turning inlet, some improvements are still required for TBCC inlet. This paper proposed a new designed variable-geometry inlet with smooth compression surface based on a high-external-compression flow pattern. So the flow structure in compression duct can be improved and the performance of the inlet can be enhanced. This approach 


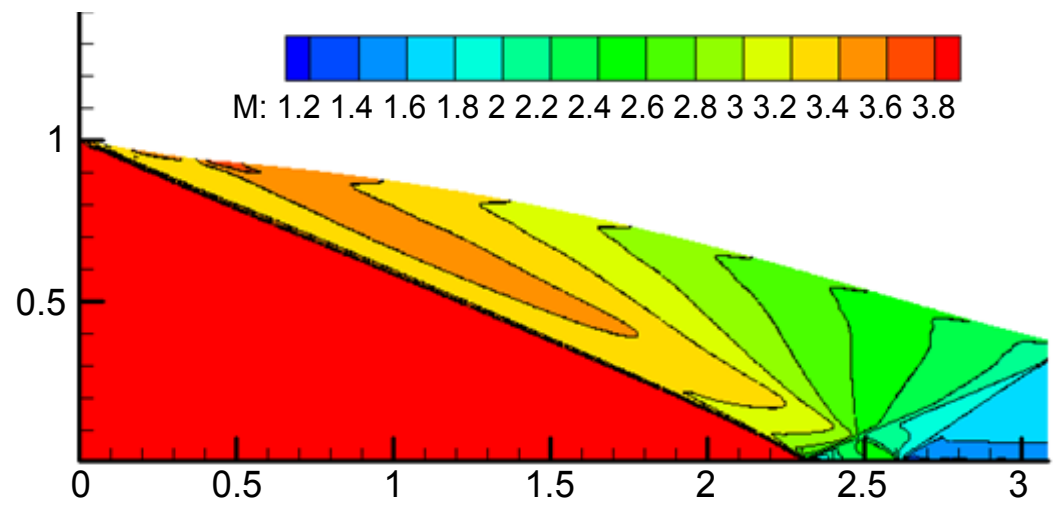

Figure 5: Two-dimensional internal conical flow of $\mathrm{C}$ flow field.

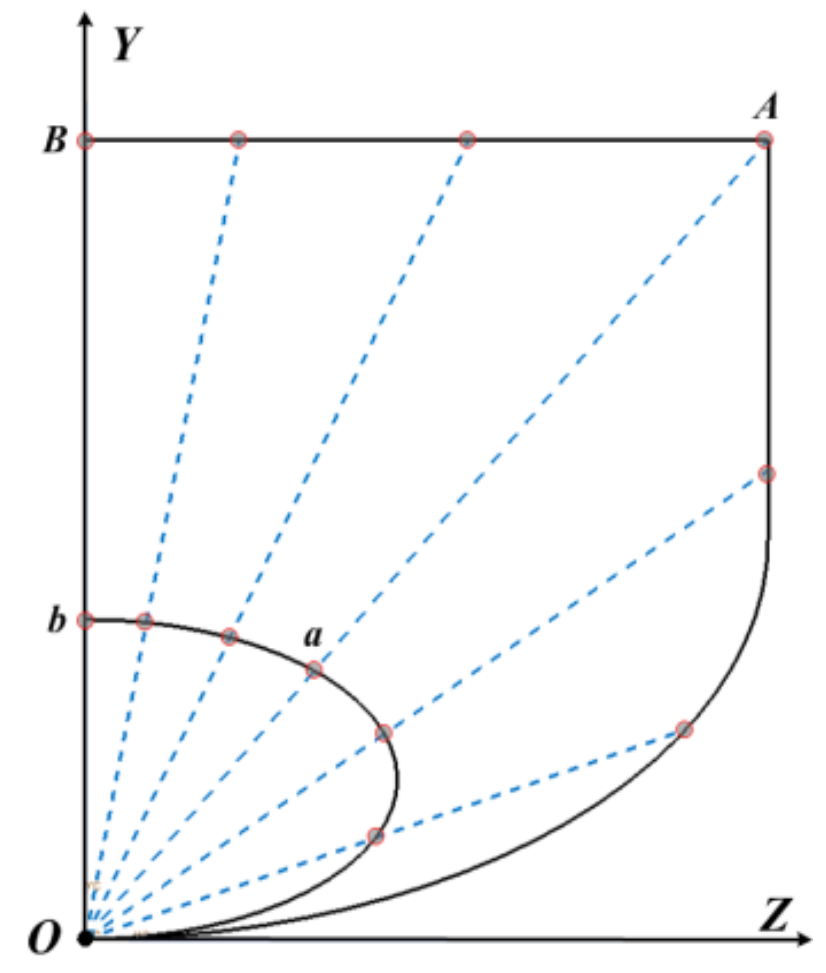

Figure 6: Sketch of results for the osculating theory.

enables a fundamental solution for problems such as the complex shock structure in the Trijet inlet, while simultaneously maintaining the high mass flow capture characteristics.

\section{Original Profile Design of Internal Waverid- er Inlet at the Design Point}

\section{Design method of internal waverider inlet}

Based on our group's previous studies reported in $[15,16]$, the ICFC flow field showed in Figure 5 is adopted as the basic flow field for IWRI. And it is acknowledged that the aerodynamic performance of a three-dimensional inward turning inlet is closely related to the corresponding basic flow field. But it can be noticed from Figure 6 that there exists a local expansion zone in the basic ICFC flow field which reduces the compression performance of IWRI inlet ultimately.

The IWRI inlet is obtained on the basis of the axisymmetric osculating theory. As showed in Figure 6 , the configuration of the three-dimensional inlet can be simplified into a collection of two-dimensional osculating planes, such as $\mathrm{OAa}$ and $\mathrm{OBb}$. If the incident shock is close to the lip in each osculating plane, the full flow capture ability of the inlet can be guaranteed, and in fact, the flow pattern in the osculating plane is similar to the responding basic flow field.

In this paper, the shape of the upwind section is of the square class for favourable matching with the forebody of the aircraft. Since previous research has indicated that a circular combustion chamber can bear a smaller frictional resistance and heat load, the exit shape is either a circle or an ellipse to match with the downstream combustion chamber. In addition, the design Mach number of the IWRI inlet is 4.0 while the design flight height is $22 \mathrm{~km}$. The design mass flow rate of IWRI inlet is 6.5 $\mathrm{kg} / \mathrm{s}$, with an aspect ratio of 1.75 for the shape of the upwind section and a contraction ratio of 5.9.

\section{Improvement of the starting ability of the in- ternal waverider inlet}

Generally, TBCC inlets need to amplify the throat to ensure the starting performance of the inlet, when the working Mach number is lower than design Mach number. But in fact, if the throat is extend to rather larger, it will increase the weight and the structure complexity of the inlet. Therefore, it 


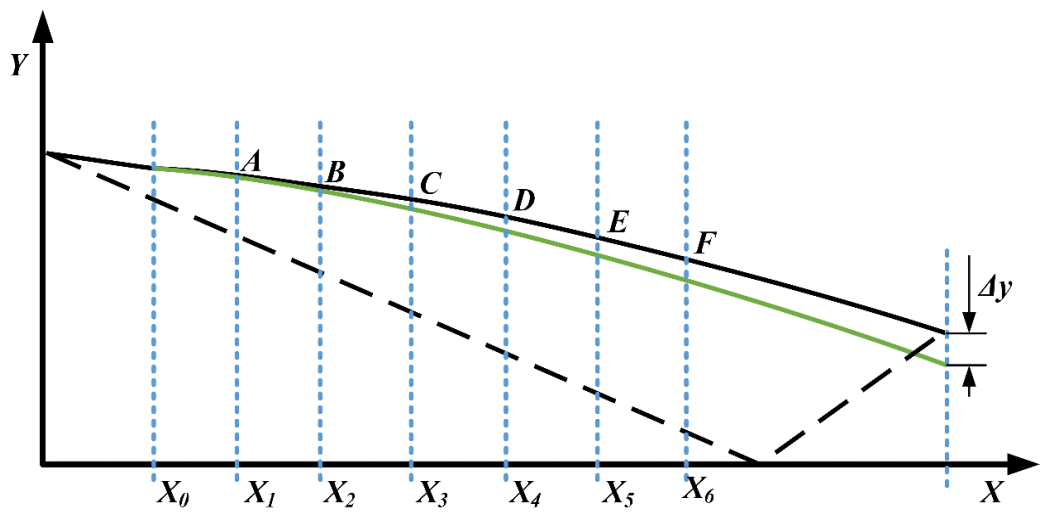

Figure 7: Schematic of the function to improve the basic internal conical flow of $\mathrm{C}$ flow field.
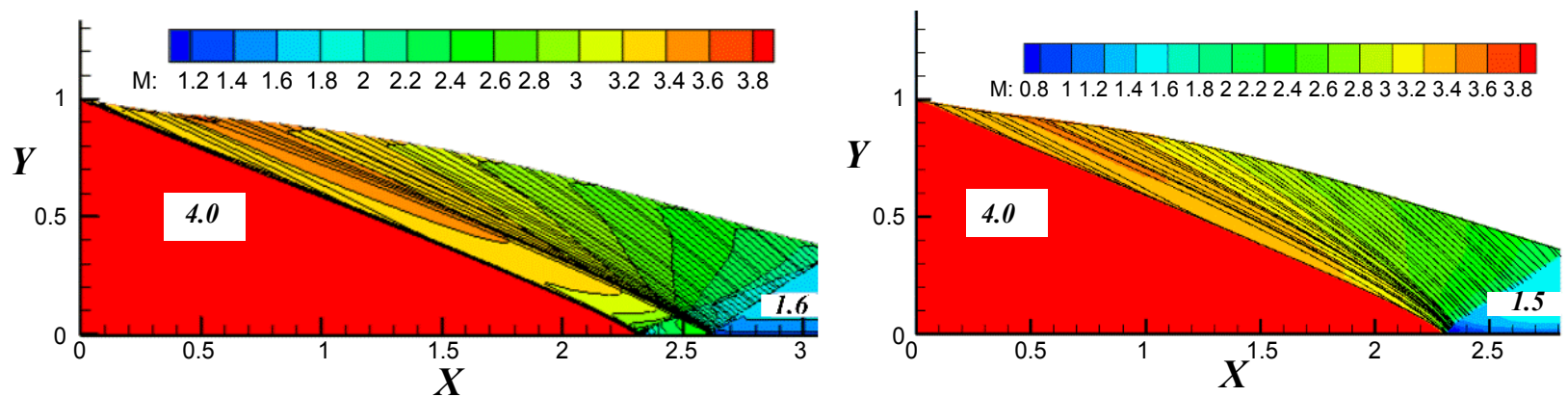

Figure 8: Comparison of the internal conical flow of $\mathrm{C}$ and improved flow fields.

is desired that the inlet can spill the needless flow under lower flight speed.

The IWRI inlet is with good mass flow capture ability, the mass flow coefficient is high with value 0.87 even in Mach 2.0 [17]. Unfortunately, excessive capture mass flow of IWRI inlet will result in a bad starting ability in lower Mach status. One of the methods is to improve the starting ability of the IWRI inlet to push down the Busemann compression curve of the original ICFC flow field [9]. And six different functions are given in [9] to improve the basic ICFC flow field.

Considered that the gradient of the starting and ending positions of inverse tangent function is small which ensures the smooth transition of the compression curve. So here a new function used inverse tangent is proposed: The initial Busemann compression curve is generated to offset a certain distance $\Delta \mathrm{y}_{0}=\mathrm{K}^{*} \arctan \left(\mathrm{X}-\mathrm{X}_{0}\right)$ from the original y coordinate. Then segmentally adjust the compression curve slightly with a distance of $\Delta \mathrm{y}_{\mathrm{i}}=\mathrm{K}_{\mathrm{i}}^{*} \arctan \left(\mathrm{X}-\mathrm{X}_{0}\right)$ as Figure 7 shows. The compression curve adjustment parameters $\mathrm{K}$ and $\mathrm{K}$ are showed in Table 1.
Table 1: The parameters to adjust Busemann compression curve.

\begin{tabular}{|l|l|l|l|l|l|l|l|}
\hline Item & $\mathbf{K}$ & $\mathbf{K}_{1}$ & $\mathbf{K}_{\mathbf{2}}$ & $\mathbf{K}_{\mathbf{3}}$ & $\mathbf{K}_{\mathbf{4}}$ & $\mathbf{K}_{\mathbf{5}}$ & $\mathbf{K}_{\mathbf{6}}$ \\
\hline Value & 0.025 & 0.005 & 0.009 & 0.010 & 0.012 & 0.012 & 0.005 \\
\hline
\end{tabular}

The characteristic line displayed in Figure 8 is the corresponding Mach line at the emitting point of the compression curve, and the line spacing reflects the degree of airflow compression (the lines gathering means compression) or expansion (the lines dispersing means expansion). Comparison of the improved ICFC+ flow field and the original ICFC flow field shows that the local expansion region following the initial shock is decreased. And the characteristic lines generated from the compression curve are gathered as close as possible to the cowl lip point, thus raising the external compression ratio. Besides, the compressing ability of the basic flow field is improved within a shorter length as the Mach number after the reflected shock is reduced from 1.60 to 1.55 for the same upstream speed. In summary, the improved ICFC+ flow field with a higher external compressing ratio is beneficial for relieving the mass burden under low Mach num- 

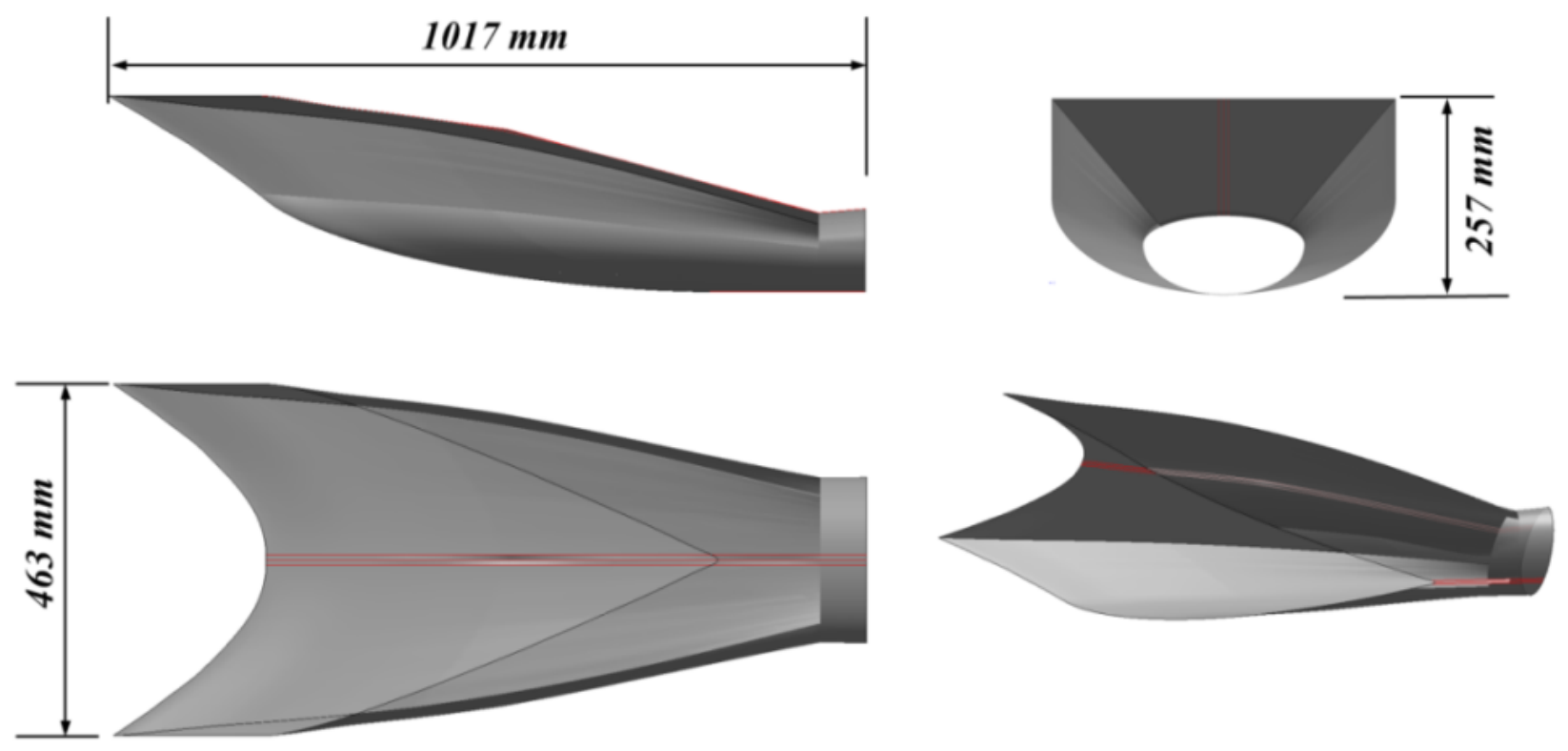

Figure 9: Internal waverider inlet with a high ratio of external compression.

bers by larger spilling flow.

Based on the improved ICFC+ flow field, the osculating axisymmetric theory mentioned in section of Design method of internal waverider inlet is used to generate the IWRI inlet with a higher external compression ratio. The three-dimensional configuration of the IWRI inlet is showed in Figure 9.

Variable-geometry Internal WaveRider Inlet Design for Turbine-Based Combined Cycle Power

\section{Geometric transformation method of internal waverider inlet with smooth compression sur- face}

For the IWRI inlet with a design Mach number of M4.0, the mass flow coefficient of the IWRI at M2.0 is up to 0.87 [15]. In order to prevent choking of the airflow, the method of enlarging the throat is adopted in this paper. And the throat area in lower Mach numbers can be estimated according to the one-dimensional flow analysis method based on formula (1). The formula is assumed that the air compression process is steady, adiabatic and isentropic from the entrance to the throat. According to the previous researches of our group, the total pressure recovery is approximately 0.85 and the Mach number of the throat is in the range of M1.11.2 in Mach 2.5 condition. So the throat area is approximately 4.8 times larger than the area of the design point.

$$
\dot{m}_{t h}=K \frac{\sigma_{t h} P_{t h}^{*} q\left(M_{t h}\right) A_{t h}}{\sqrt{T_{t h}^{*}}}=\varphi_{t h} K \frac{P_{\infty}^{*} q\left(M_{\infty}\right) A_{i n}}{\sqrt{T^{*}}}
$$

Two-dimensional variable inlet always rotates a selected movable surface around a single axis to enlarge the throat area. As the throat area of the IWRI inlet should be enlarged by 4.8 times in Mach 2.0 conditions, the traditional geometric transformation method is not sufficient to ensure that the inlet can be started.

So, this work presented a new geometric transformation method. The IWRI compression surface is divided into two parts along the symmetry plane [15] (the blue surface shows in Figure 10) and rotate the two compression surfaces around each axis to expand the throat. The enlarged IWRI inlet can obtain the starting ability in low Mach conditions. As showed in Figure 5, the cut position of the movable compression surface is a distance from the inlet entrance. So that a rotation of the inlet surface would not change the depend surface which generates the first incident shock wave of the IWRI inlet.

Over the full range of Mach number conditions, the boundary between the fixed and movable compression surfaces requires special attention to ensure a smooth shape of the throat section. As presented in Figure 11, the rotation axes (I and I') are both in the $\mathrm{YOZ}$ plane with an angle $\theta$ to the $\mathrm{OZ}$ axis. According to the one-dimensional flow analysis, $\theta$ is equal to $30^{\circ}$ to enlarge the throat area as much 


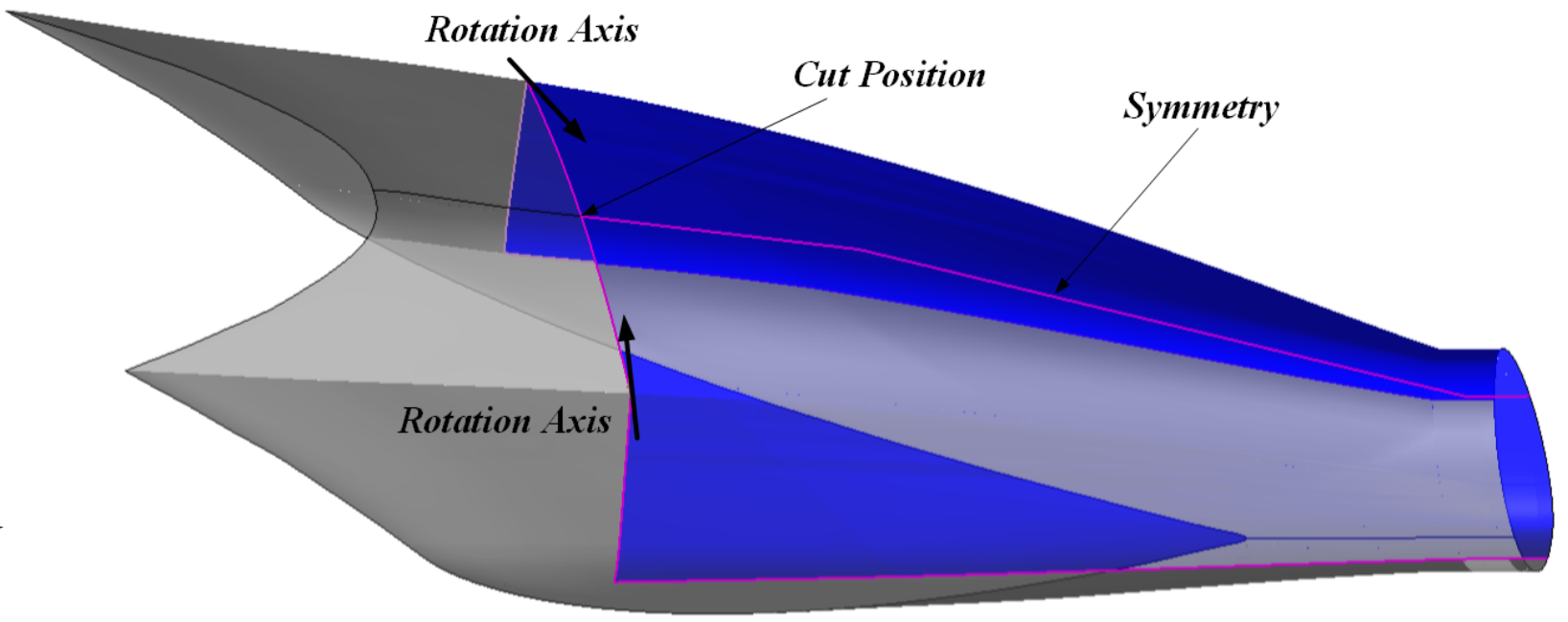

Figure 10: Movable compression surfaces in the internal waverider inlet.

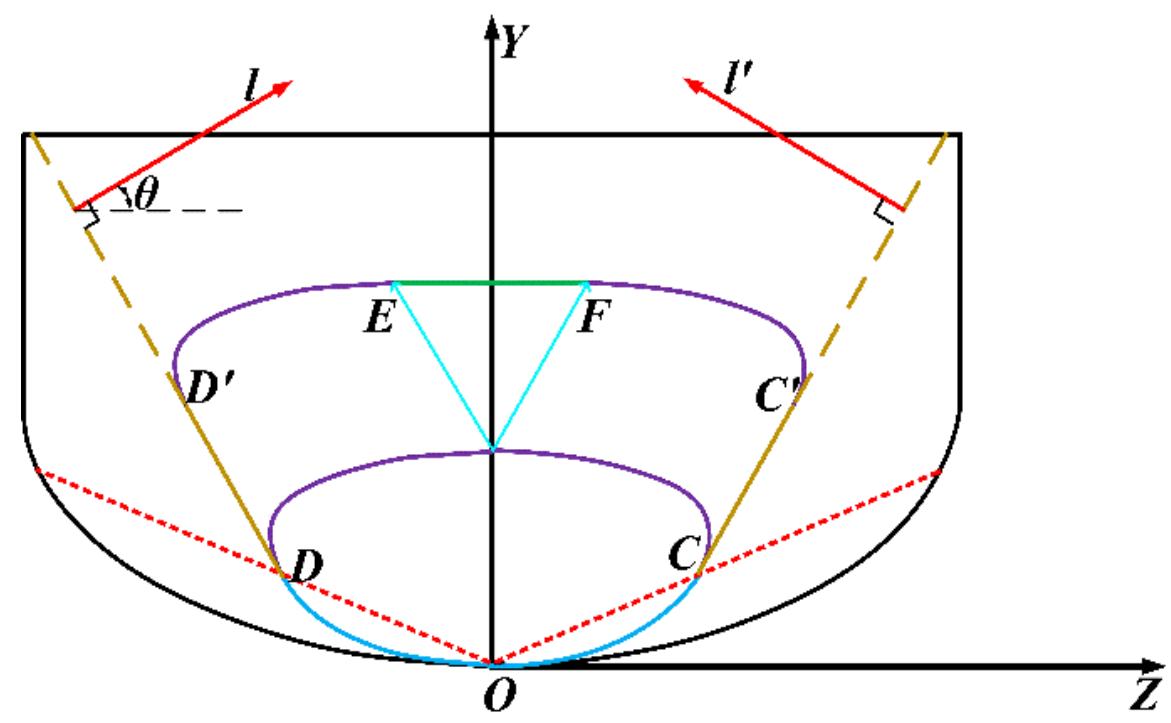

Figure 11: Schematic of an enlarged throat area.

as possible with the same rotation angle. The compression surface of the variable-geometry IWRI inlet in this paper keeps smooth and its actuation can been seen from the cross section showed in Figure 11. The movable throat section in design condition is divided at points $C / D$ by the straight lines $C C^{\prime}$ and DD' which are perpendicular to the rotation axes. The moveable throat profiles are always tangent to $C C^{\prime} / D D^{\prime}$, so the cross sections along the flow direction can keep smooth when the IWRI inlet geometry changes.

As Figure 11 shows, the movable profile CD changes to profiles C'F and D'E after varying the inlet geometry. Obviously, there are gaps between the moveable surfaces and the fixed surfaces. To ensure sealing the hot compressed air in low Mach conditions, it is necessary to add sealing surface to the IWRI inlet. The sealing surface is also showed in Figure 11 while $C C^{\prime} / D^{\prime}$ at the side walls is fixed and $\mathrm{EF}$ at topside is movable. In the process of variable geometry, the throat shape changes from the design elliptic line OCD to the enlarged curve OCC'EFD'DO which still keep continuous.

The three-dimensional variable geometry of IWRI inlet is showed more clearly in Figure 12. The grey parts are fixed compression surfaces and the blue parts are movable compression surfaces. When the inlet geometry changes, the sealing surfaces are added to prevent high-speed airflow running away. The orange parts (CC' and DD' in Figure 


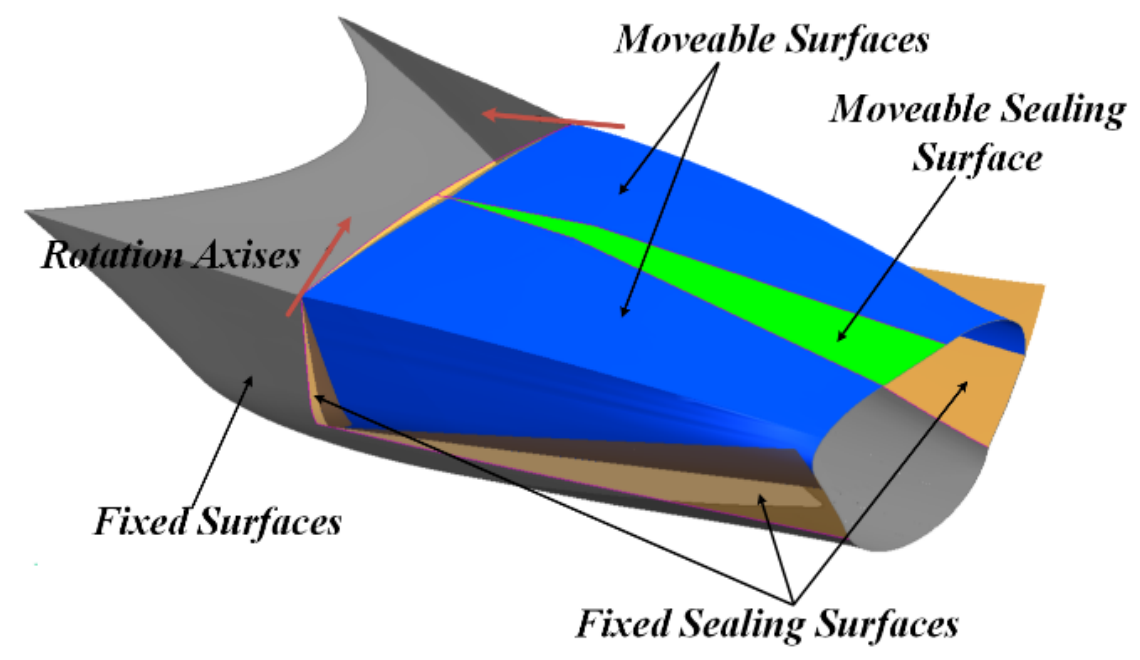

Figure 12: Internal waverider inlet for an enlarged throat.
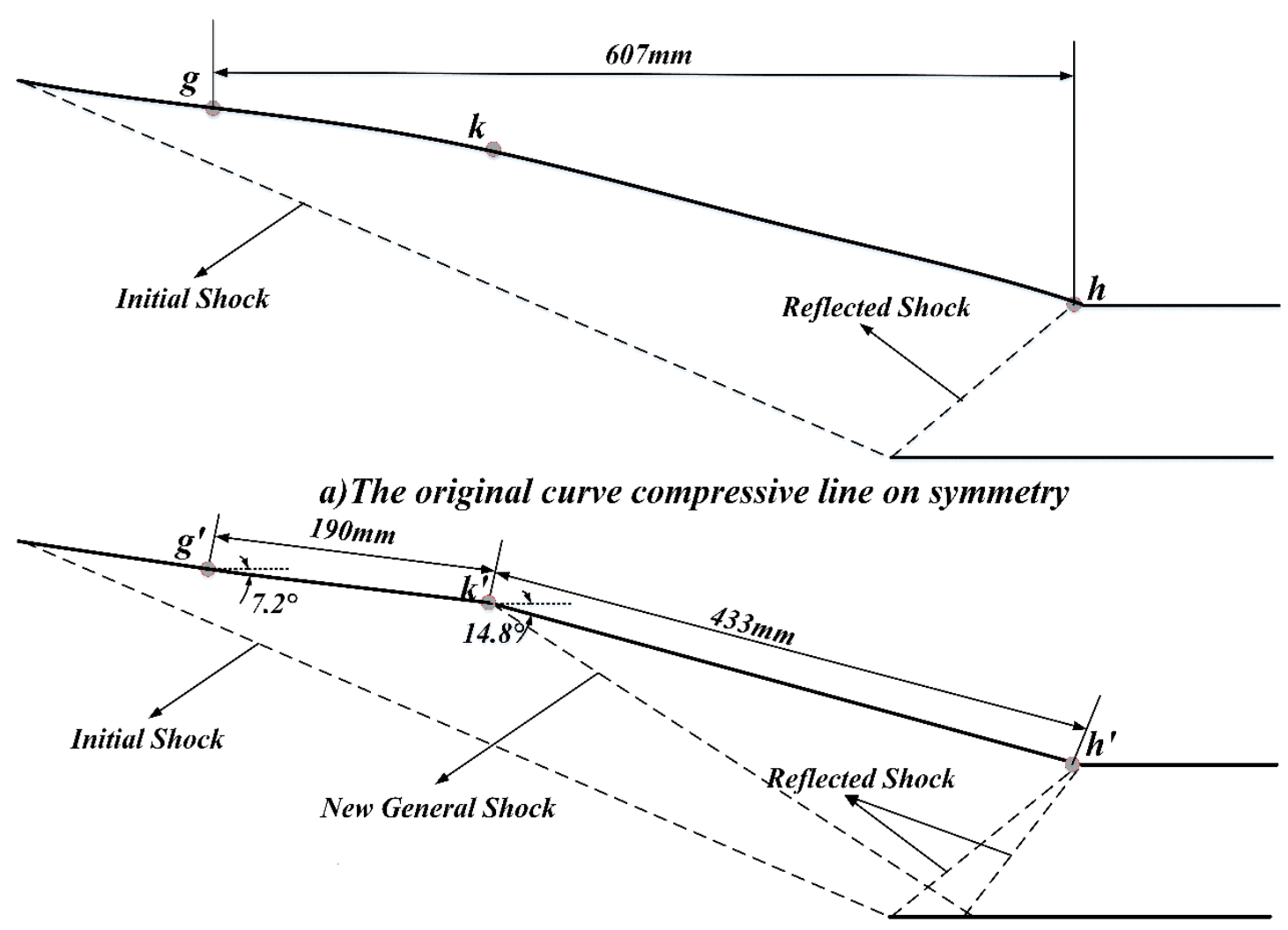

b)The polyline compressive line on symmetry

Figure 13: Compressive line for symmetry and the osculating plane.

11) are fixed sealing surfaces which are obtained by rotating the side-edge lines of the movable compression surface around the axes. The green part (EF in Figure 11) is movable sealing surface which is placed on the topside to cover the gap between two separate movable compression parts. Therefore, the variable-geometry IWRI inlet can be ob- tained with smooth compression surface and amplified throat.

\section{Modification design for the sealing of topside surface gap}

As mentioned in last section there is a gap in the topside of the inlet compression surface during 
variable-geometry actuation, and it requires to add a movable sealing surface. As the edge of the movable compression surface is a curve and required movable sealing surface is with different geometry shape in different Mach conditions. So it is difficult to design the movable sealing surface to guarantee air tightness over the full range of inlet's transformation (responding to all range of flight speed). In this paper, a movable folded plate in the topside is used to seal the gap in different operational conditions.

As Figure 13 shows, the edge line of the movable compression surface can be displayed as the compression line at the symmetry plane. And we change the curve line of the symmetry to polyline firstly. The curve compression line gkh is modified to two straight lines gh' and h'k on the symmetry plane. In order to ensure that the two compression lines are as close as possible, $g h^{\prime}$ is tangent to the curve gkh at the point $g$ and $h$ 'k is tangent to the curve gkh. The detailed parameters of the compression lines are showed in Figure 13.

In order to reduce the influence of the polyline of the symmetry compression line on the IWRI inlet, the centre position of the osculating planes is changed from $\mathrm{O}$ to $\mathrm{O}_{1} / \mathrm{O}_{2}$ as Figure 14 shows. And the distance $\mathrm{m}$ from symmetry line is $6.5 \mathrm{~mm}$. So the symmetry OP is with polyline compression line while the osculating planes such as $\mathrm{O}_{1} \mathrm{~N}$ and $\mathrm{O}_{2} \mathrm{Q}$ still keep curve compression line. Finally, a surface which translated from the curve line of the osculating plane to the polyline on the symmetry is inserted to the IWRI inlet. The inserted plane is added between the symmetry planes (OP) and the first osculating plane $\left(\mathrm{O}_{1} \mathrm{~N}\right.$ or $\left.\mathrm{O}_{2} \mathrm{Q}\right)$. This geometric tran-

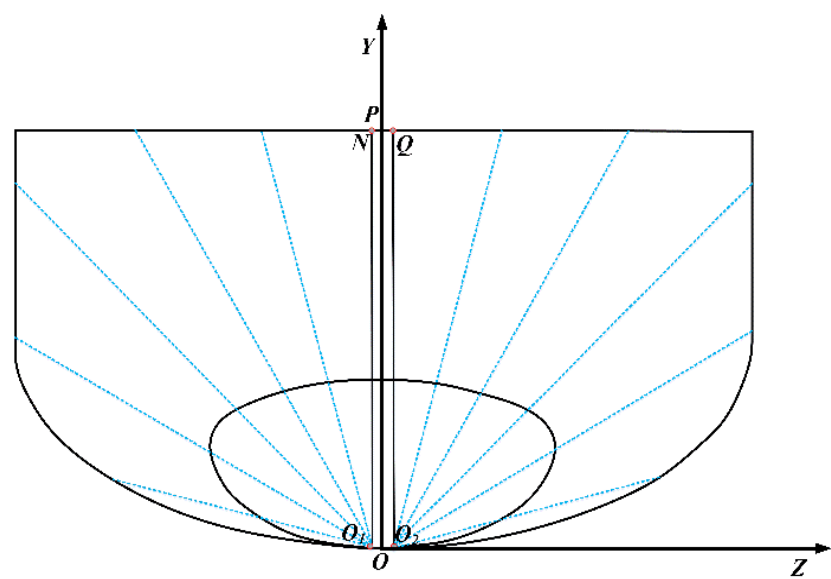

Figure 14: New arrangement of the osculating planes. sition surface is showed as the red part in Figure 15. And the aspect ratio of the new inlet is 1.8 . In this way, the profile of the gap in the back face of the IWRI inlet maintains flat surfaces in the case of arbitrary freestream Mach numbers, and the gap can be sealed well by the corresponding planes.

The variable-geometry design method does not change the upstream part of compression surface which is required by the IWRI inlet to generate the initial shock at the entrance. Thus, a high mass flow coefficient is maintained over a wide range of freestream Mach numbers. Furthermore, the enlarged throat resulting from the variable-geometry actuation can ensure a successful start ability of the IWRI TBCC inlet, and keep the throat Mach number in the range of M1.1-M1.5. In addition, the cross-sectional shape of the enlarged throat is smooth and maintains a continuous curvature, giving rise to excellent flow quality due to the absence of corner flow phenomena.

\section{Flow Characteristic Analysis of the Tur- bine-Based Combined Cycle Inlet}

To analyse the IWRI TBCC inlet, CFD simulations for 3-D inlet model are performed by commercial software, CFX. The structured grid is generated by ANSYS ICEM, and the total number of mesh points is 1.5 million. The standard K-E turbulence model is adopted for numerical simulation, and the verification and validation of the numerical method are described in $[8,18]$. From the reference [8], this CFD method is accurate for the inlet which work Mach number is of the range of M2.0-4.0.

The results of the IWRI inlet at the design point (M4.0) are displayed as follows. In Figure 16, the Mach contours on the typical osculating planes reveal that the flow characteristics of the three-di-

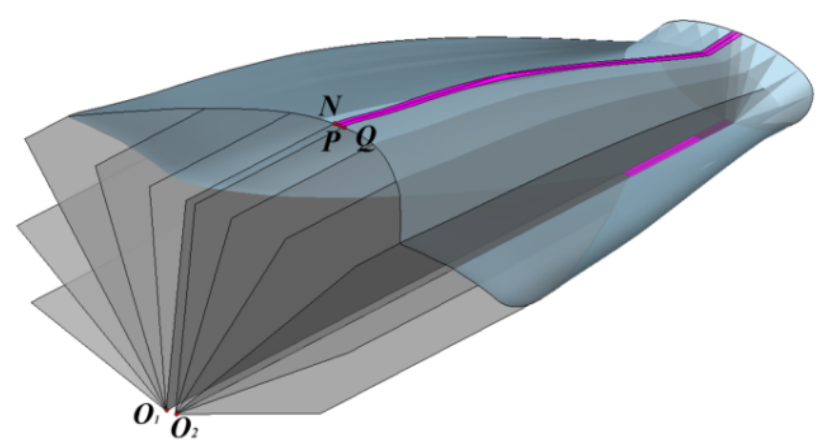

Figure 15: Three-dimensional arrangement of the osculating planes. 


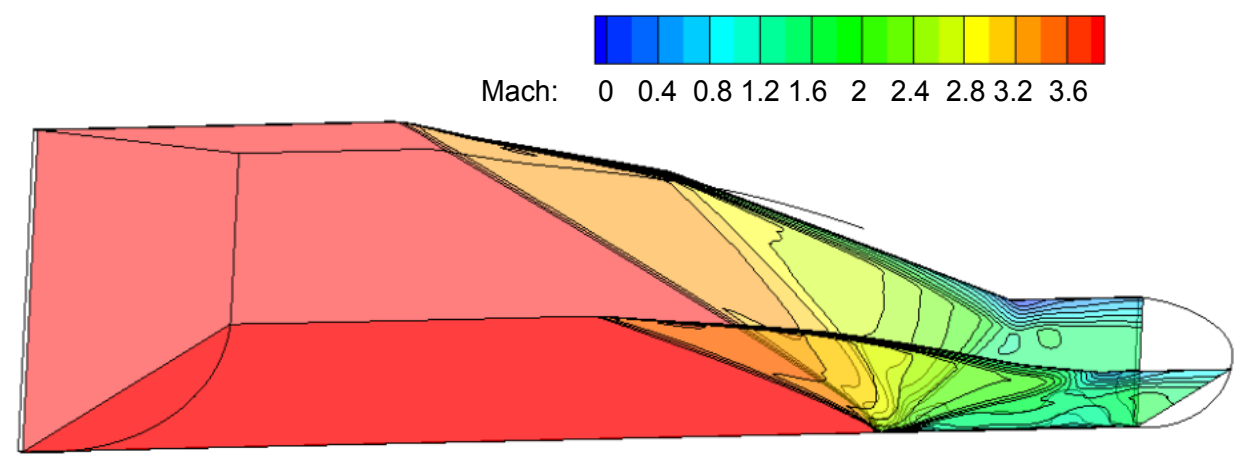

Figure 16: Mach contours in typical osculating planes (M4.0).

Mach: $0.20 .6 \quad 1 \quad 1.41 .82 .22 .6 \quad 3 \quad 3.43 .8$

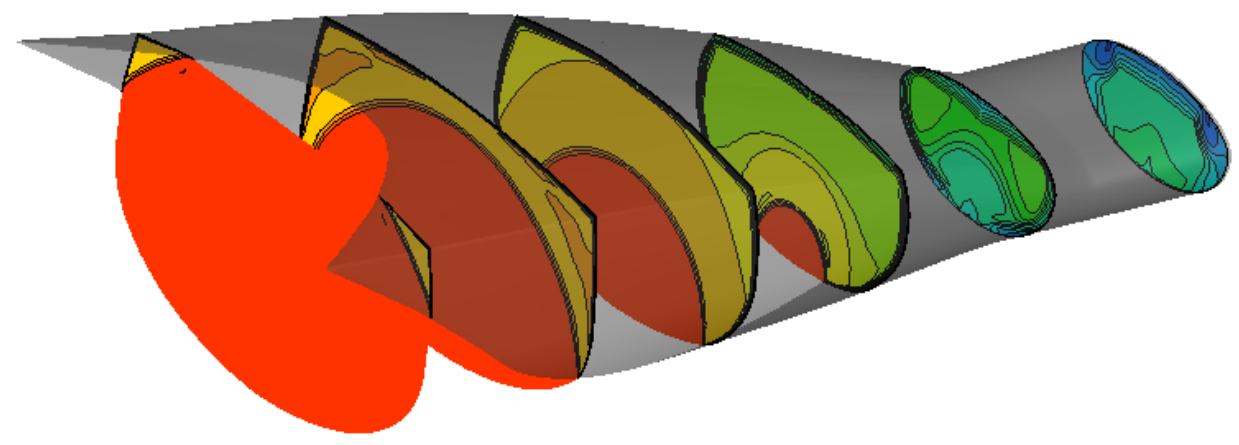

Figure 17: Mach contours on cross-sectional planes along the passage (M4.0).
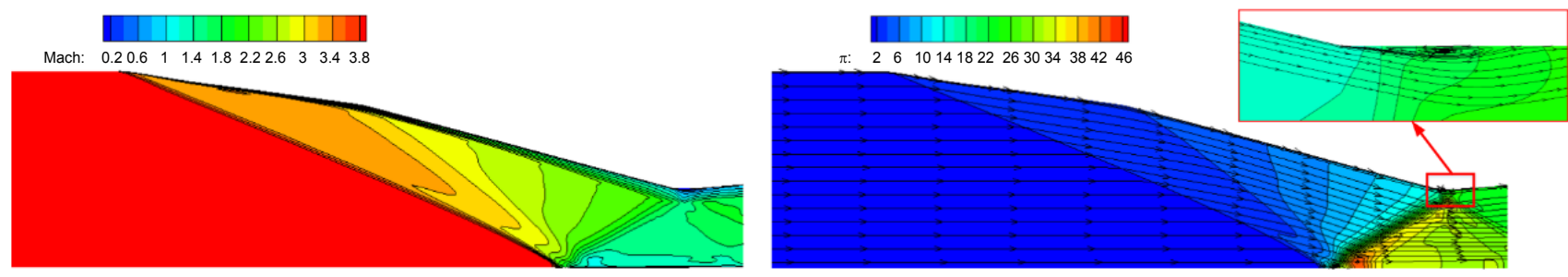

Figure 18: Mach and pressure distribution of $\mathrm{O}_{2} \mathrm{Q}$ (M4.0).

mensional inlet (such as the shock structure and flow pattern), are similar to the two-dimensional basic flow field. The incident shock of the inlet is circularly shaped at every cross-section along the flow direction, as showed in Figure 17, and it covers the entrance of the inlet to capture $100 \%$ of the upstream airflow. The high mass flow coefficient favours a low drag of external flows and provides sufficient thrust for the aircraft. Figure 18 shows that there exists a shock/boundary interaction near the position of the shoulder because the reflected shock is influenced by the viscosity, causing little flow separation.

Comparison of Mach contours for M4.0 between the symmetric plane OP (showed in Figure 18) and the $O_{2} Q$ plane (showed in Figure 19) indicates that an oblique shock will be generated at point $\mathrm{k}^{\prime}$ (shown in Figure 13) and there are almost same shock-wave structures as the upper diagram in Figure 13, when the compressing curve of the symmetric surface is changed to a straight line. Fortunately, this phenomenon does not have a significant effect on the flow or shock structures of other osculating planes. 


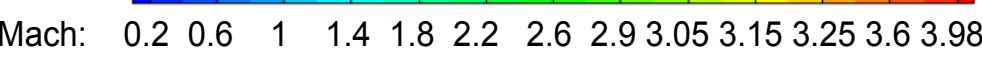

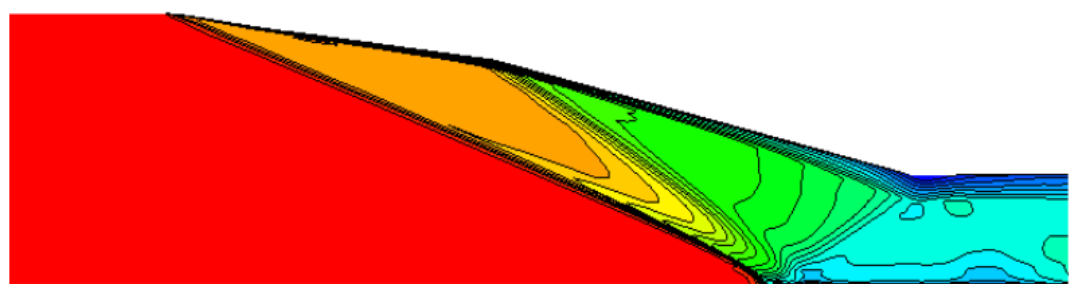

Figure 19: Mach contours for the symmetry plane (M4.0).

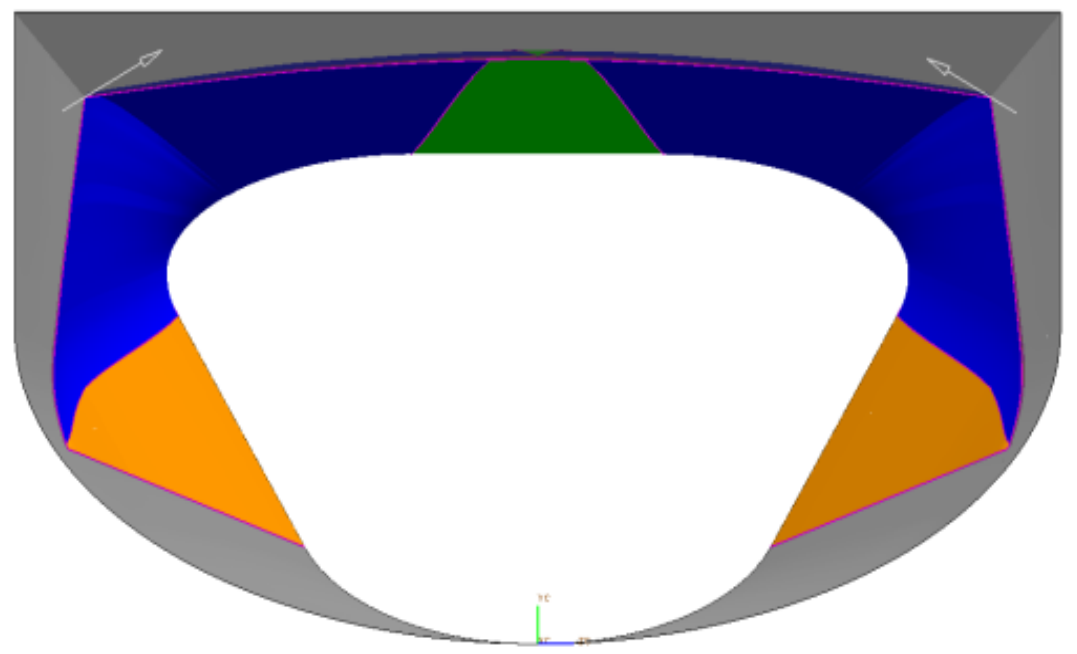

Figure 20: Front view of an amplified throat for M3.0.

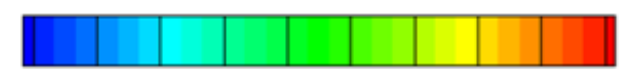

Mach: $0.2 \quad 0.50 .81 .1 \quad 1.41 .7 \quad 2 \quad 2.32 .62 .9$

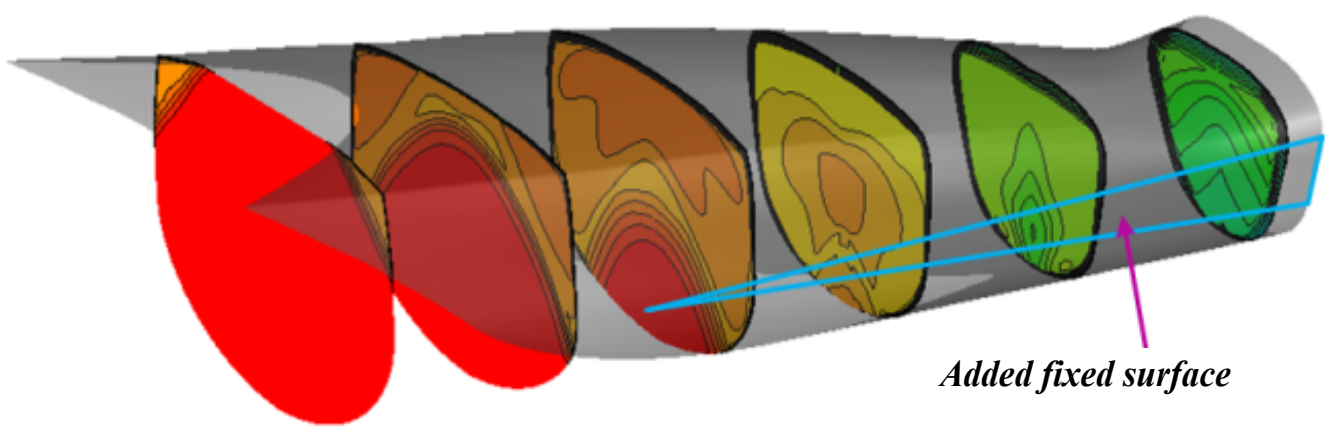

Figure 21: Mach contours on cross-sectional planes along the passage (M3.0).

In low Mach number work status ( $M=3.0)$, the throat of the IWRI is amplified for the starting as shown in Figure 20, with two fixed sealing plates (orange parts) added in the side-walls and a movable sealing plate (green part) on the top-wall (as mentioned in Figure 11 and Figure 12). Figure 21 presents the Mach number distribution of the cross-sections along the passage and indicates that the supersonic flow is effectively compressed by the added sealing plates which be presented as key parts of this new variable-geometry design for TBCC inlet; the inlet also keeps the three-dimen- 

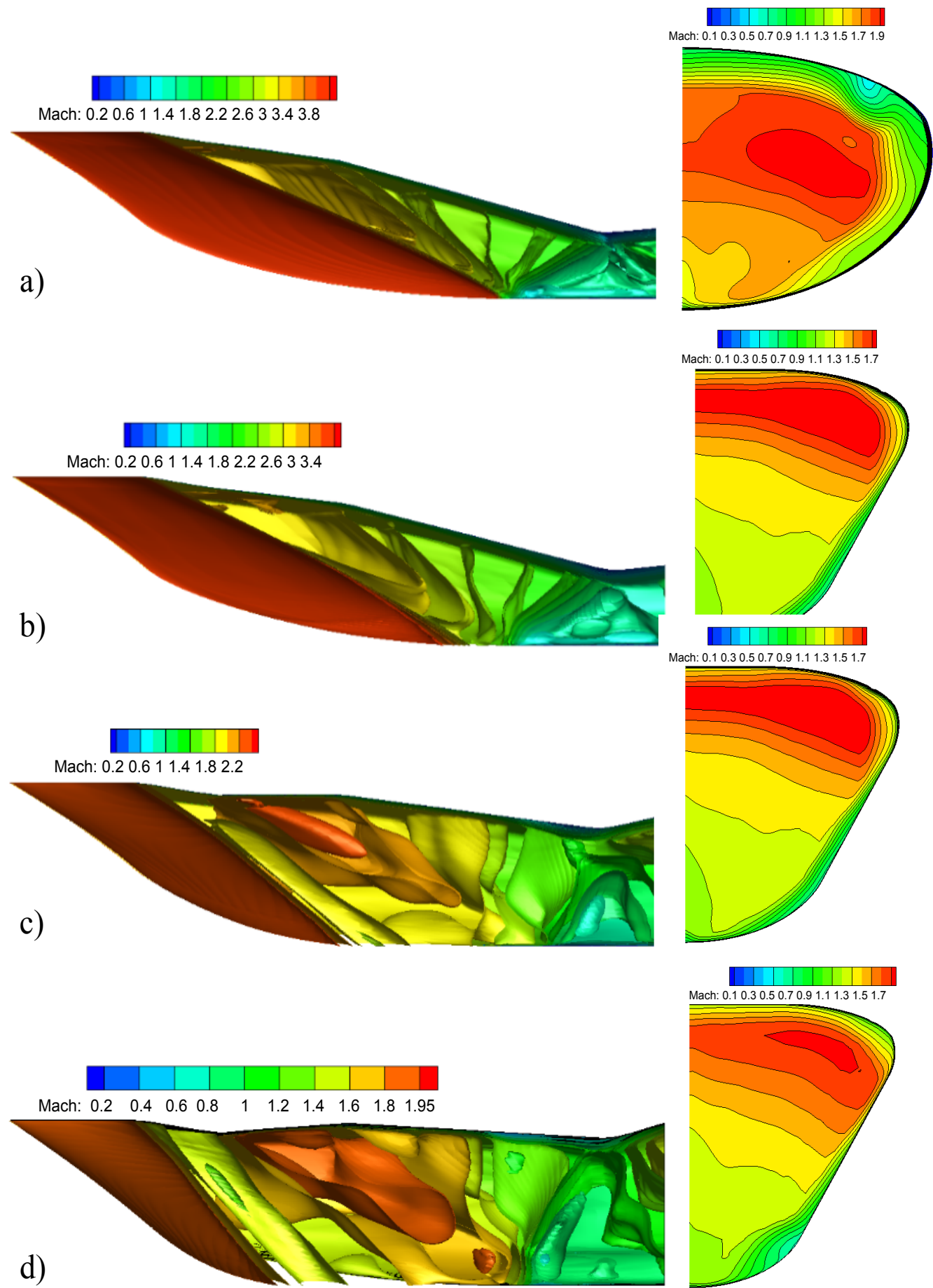

Figure 22: Mach contours on cross-sectional planes along the passage (M3.0): a) For the state of M4.0; b) For the state of $\mathrm{M} 3.5 ; \mathrm{c}$ ) For the state of M2.5; d) For the state of M2.0.

sional compressing ability and does not appear any corner flow.

Figure 22 shows typical Mach number contours for the TBCC inlet in different upstream conditions varying from M4.0 to M2.0. When the TBCC inlet operates at the design point the initial incident shock stands at the edge of the entrance and captures the full upstream flow. However, at the off-design points, this shock gradually moves away from the cowl lip to the upstream and the spillage flow increases with Mach number decreasing. Nevertheless, the side walls of the inlet can still achieve an on-lip shock, which is the key factor guaranteeing its high mass coefficient characteristics. The Mach number distribution at the throat sections shows that the profiles of the Mach contour lines are smooth. There is no corner flow at the throat 
Table 2: Performance parameters of the TBCC inlet at typical Mach numbers.

\begin{tabular}{|l|l|l|l|l|l|l|}
\hline Free stream condition & $\varphi$ & $M_{t}$ & $\sigma_{e}$ & $\eta_{k_{e}}$ & $\pi_{e}$ & $\alpha$ \\
\hline M4.0 & 0.9983 & 1.4901 & 0.7713 & 0.9759 & 30.7988 & $0^{\circ}$ \\
\hline M3.5 & 0.9677 & 1.3351 & 0.8326 & 0.9781 & 21.1177 & $4.6^{\circ}$ \\
\hline M2.5 & 0.9027 & 1.2805 & 0.9185 & 0.9803 & 5.8905 & $8.7^{\circ}$ \\
\hline M2.0 & 0.8625 & 1.0558 & 0.9215 & 0.969 & 3.288 & $13.3^{\circ}$ \\
\hline
\end{tabular}

section, and the exit flow of inlet is relatively good considering the exit flow of typical other type inlets (such as two-dimensional planar inlet).

\section{Aerodynamic Performance Analysis of the Turbine-Based Combined Cycle Inlet}

As the flight speed decreases, the rotation angle of the movable compression walls is increased to enlarge the throat area for starting the inlet under low Mach number conditions, and the rotation angle shows a nonlinear relationship with the flight speed. The aerodynamic performance based on numerical simulation results under different typical Mach numbers (presented in Table 2) indicates that the variable-geometry TBCC inlet exhibits the advantages of a high mass flow coefficient and a low total pressure loss with strong compressing ability, which arise from the IWRI inlet.

Compared to the IMX inlet, a typical binary inlet mentioned in [7], the new designed variable-geometry IWRI inlet is with higher compression efficiency at Mach 4.0 condition. And compared to the ATREX inlet, a variable geometry axisymmetric inlet mentioned in $[5,19]$, the variable-geometry IWRI inherits high mass airflow capture coefficient even in off-design conditions and maintains a rather higher total pressure recovery. Such excellent performances result from the new design method of geometry transforming without any convex part or corner. It is obvious that these advantages are beneficial for increasing the engine thrust, which is of great significance for improving the overall performance of the TBCC.

\section{Conclusion}

In this paper, an appropriate variable-geometry inlet design without any convex part or corner is proposed for a Turbine-Based Combined Cycle system, based on the Internal Waverider Inlet with a high external compression ratio. Using CFD numerical simulations, the flow field characteristics and aerodynamic performances of different operation- al states are analysed, and the following results are obtained.

1. An improved basic Internal Conical Flow of $\mathrm{C}_{+}$ flowfield with a high external compression ratio can promote the starting ability of the Internal Waverider and Turbine Based Combined Cycle inlet and reduce the variable-geometry burden of the throat at low Mach numbers because the extent of mechanical movement is decreased.

2. A variable-geometry Internal Waverider Inlet design without any convex part or corner is proposed for the Internal Waverider and Turbine Based Combined Cycle inlet. The compressive line profile of symmetric plane is changed to straight lines from the original curve, and the movable compression surface is set for sealing the airflow, together with the fixed compression surfaces on the lateral side. The variable-geometry Internal Waverider Inlet can start and operate efficiently over the full range of Mach numbers. The shape of the throat section remains smooth, and the curvature is continuous, which is beneficial for improving the exit flow quality of the Internal Waverider Inlet.

3. In typical Mach number conditions, the entire surfaces of the Internal Waverider and Turbine Based Combined Cycle inlet (including the lateral fixed sealing plates) can effectively compress the airflow, giving rise to a three-dimensional compressing effect. The shock structure in the flow field is relatively simple and clear (because of no convex part), there is no obvious corner flow in the passage, the aerodynamic parameters in the throat and exit section are well-distributed, and the exit flow is with high quality.

4. Numerical simulation results show that the variable-geometry Turbine-Based Combined Cycle inlet exhibits multiple advantages, such as high mass flow capture ability, low total pressure loss and strong compressing ability, which are highly significant for improving the overall per- 
formance of the Turbine-Based Combined Cycle system.

5. Although there are errors in calculations in this article, the CFD turbulence model adopted in calculations has been checked, and the errors are within the tolerable range. So the results of calculations are reliable.

\section{Acknowledgements}

Inlet team members in the college of Power and Energy of NUAA are gratefully acknowledged for their cooperation.

\section{Funding}

This work is supported by the National Program on Key Basic Research Project of China (No.2014CB239602) and the National Natural Science Foundation of China (No.11372134). This work is also part of Project KYLX15-0261, supported by the Funding of the Jiangsu Innovation Program for Graduate Education and the Fundamental Research Funds for the Central Universities.

\section{References}

1. Hideyuki T, Hisao F, Kazuo S, Tetsuya M, Takayuki $K$, et al. (2003) Design study on hypersonic engine components for TBCC space planes. 12th AIAA International Space Planes and Hypersonic Systems and Technologies, American Institute of Aeronautics and Astronautics, USA.

2. Snyder LE, Escher DW, DeFrancesco RL, Gutierrez JL, Buckwalter DL (2004) Turbine based combination cycle (TBCC) propulsion subsystem integration. 40th AIAA/ASME/SAE/ASEE Joint Propulsion Conference and Exhibit, American Institute of Aeronautics and Astronautics, USA.

3. Moses PL, Rausch VL, Nguyen LT, Hill JR (2004) NASA hypersonic flight demonstrators - Overview, status, and future plans. Acta Astronautica 55: 619-630.

4. Colville JR, Starkey RP, Lewis MJ (2005) Extending the flight mach number of the SR-71 inlet. 13th AIAA/ CIRA International Space Planes and Hypersonic Systems and Technologies Conference, American Institute of Aeronautics and Astronautics, USA.

5. Colville JR, Starkey RP, Lewis MJ (2006) Axisymmetric inlet design for combined-cycle engines. Journal of Propulsion and Power 22: 1049-1058.

6. Albertson CW, Emami S, Trexler CA (2006) Mach 4 test results of a dual-flowpath, turbine based combined cycle inlet. 14th AIAA/AHI International Space Planes and Hypersonics Systems Technologies Con- ference, American Institute of Aeronautics and Astronautics, USA.

7. Slater JW, Saunders JD (2009) CFD simulation of hypersonic TBCC inlet mode transition. 16th AIAA/ DLR/DGLR International Space Planes and Hypersonic Systems and Technologies Conference, American Institute of Aeronautics and Astronautics, USA.

8. Zuo F, Huang G, Xia C (2016) Investigation of internal-waverider-inlet flow pattern integrated with variable-geometry for TBCC. Aerospace Science and Technology 59: 69-77.

9. Zuo F, Huang G (2017) A preliminary overview analysis on the internal waverider inlets for ramjet. 21st AIAA International Space Planes and Hypersonics Technologies Conference, American Institute of Aeronautics and Astronautics, USA.

10.Walker SH, Rodgers $F$ (2005) Falcon hypersonic technology overview. 13th AIAA/CIRA International Space Planes and Hypersonic Systems and Technologies Conference, American Institute of Aeronautics and Astronautics, USA.

11.Walker S, Tang M, Morris S, Mamplata C (2008) Falcon HTV-3X - A reusable hypersonic test bed.15th AIAA International Space Planes and Hypersonic Systems and Technologies Conference, American Institute of Aeronautics and Astronautics, USA.

12.Siebenhaar A, Bogar TJ (2009) Integration and vehicle performance assessment of the aerojet "TriJet" combined-cycle engine. 16th AIAA/DLR/DGLR International Space Planes and Hypersonic Systems and Technologies Conference, American Institute of Aeronautics and Astronautics, USA.

13.Bulman MJ, Siebenhaar A (2011) Combined cycle propulsion: Aerojet innovations for practical hypersonic vehicles. 17th AIAA International Space Planes and Hypersonic Systems and Technologies Conference, American Institute of Aeronautics and Astronautics, USA.

14.O'Brien TF, Davis DO, Colville JR (2008) The advanced combined-cycle integrated inlet test program - test results. 15th AIAA International Space Planes and Hypersonic Systems and Technologies Conference, American Institute of Aeronautics and Astronautics, USA.

15.Zuo F, Huang G, Huang H, Xia C (2016) Analyzing the parent flowfield of inward turning inlet combined with variable-geometry. 52nd AIAA/SAE/ASEE Joint Propulsion Conference, American Institute of Aeronautics and Astronautics, USA.

16.You Y (2011) An overview of the advantages and con- 
cerns of hypersonic inward turning inlets. 17th AIAA International Space Planes and Hypersonic Systems and Technologies Conference, American Institute of Aeronautics and Astronautics, USA.

17. Huang $H$, Huang G, Zuo F, Xia C (2017) CFD simulation of TBCC inlet based on internal wave-rider concept. 21st AIAA International Space Planes and Hypersonics Technologies Conference, American Institute of Aeronautics and Astronautics, USA.

18. Yancheng Y, Dewang L (2007) Cross section control- lable hypersonic inlet design using streamline tracing and osculating axisymmetric concepts. 43rd AIAA/ ASME/SAE/ASEE Joint Propulsion Conference, American Institute of Aeronautics and Astronautics, USA.

19. Kojima T, Tanatsugu N, Sato T, Kanda M, Enomoto $Y$ (2001) Development study on axisymmetric air inlet for ATREX engine. 10th AIAA/NAL-NASDA-ISAS International Space Planes and Hypersonic Systems and Technologies Conference, American Institute of Aeronautics and Astronautics, USA. 